\title{
The Problems of Russian-Speaking Students of Non-Linguistic Specializations in CAE Speaking Test: Analysis of Teaching Experience
}

\author{
Galina Levitskaya \\ National Research University Higher School of Economics
}

Correspondence concerning this article should be addressed to Galina Yu. Levitskaya, English Language Department for Economic and Mathematical Disciplines, National Research University Higher School of

Economics, 26 Shabolovka St., Moscow, Russian Federation, 119049.E-mail: glevitskaya@hse.ru

\author{
Elizaveta Levitskaya \\ National Research University Higher School of Economics
}

Correspondence concerning this article should be addressed to Elizaveta Yu. Levitskaya, English Language Department for Economic and Mathematical Disciplines, National Research University Higher School of Economics, 26 Shabolovka St., Moscow, Russia, 119049. E-mail: veta542011@mail.ru

\begin{abstract}
Today Russian undergraduate students of non-linguistic specializations aspiring to careers in different spheres succeed in acquiring Certificates in Advanced English. Nevertheless, the candidates state that they experience the most serious difficulties while sitting the Speaking Test of the CAE exam as they lack oral language skills. The researched literature does not consider Russian students' predicaments purposely and gives a broad overview of the main students' concerns. This study is an attempt to explore the particular Russian students' problems of forming oral language skills arising in the process of their training for the Speaking Test and to work out the ways of their remedies. Qualitative methods have allowed finding out the highly specific nature of individual experience. The methods used in the study also included an open-ended language learning questionnaire and a survey to support the assessment of the received data. The results indicate that there are quite a number of pedagogical and educational variables that should be permanently trained and developed as they can influence students' success.
\end{abstract}

Keywords: Speaking Test of the CAE, oral proficiency, motivation, assessment, open-ended questionnaire

The Speaking Test (ST) of the CAE exam tests the candidates' level of oral proficiency in dyads or in groups of three. In four conversations the candidates must "cooperate in order to jointly construct a discourse that is both connected and coherent" (Meddingtons \& Thornbury, 2009, p. 9) using a wide range of grammatical forms and vocabulary and not simply formulate utterances in L2. As the candidates are required "to demonstrate their spoken language skills in a range of contexts" (Norris, 2004, p. 5), the speaking component of the CAE encourages teachers and students to do more mock exam papers in class to familiarize the candidates with the exam format, to cover some typical topics, and to relieve their test anxiety. A great deal of classroom research proves that "an oral component in a test considerably complicates the testing procedure, both in terms of its practicality and the way assessment criteria can be reliably applied" (Thornbury, 2013, pp. 124-125). Consequently, during the preparation course all the candidates should be interviewed regularly, as in the beginning the candidates cannot realize their weaknesses and strengths, but the washback effect of such testing on learning is clear: the candidates become aware of positive and negative sides of their oral proficiency. The observation and experience have shown that much depends on the part of the ST. Throughout the research process the attempt to answer the following 
questions investigated by a number of authors (Winn, 2005, pp. 276-277; Hamid, 2014; Hawkey, 2009) was taken: What actually transpires in class while preparing? What are the causes of misunderstanding and reasons for communication breakdowns? Which strategies are most efficient to get ready for the oral exam and why?

\section{Materials and Methods}

\section{Background}

Empirical evidence shows that any test takers' performance on oral proficiency tests is "affected by a series of variables associated with the test taker, the task and the interlocutor" (O'Sullivan, 2004, p. 129). Preparation for all parts of the ST and mock exams revealed that paired linguistic performance (and in trios especially) can depend on such variables as the gender (and age) of partners, their degree of acquaintanceship, perceived language skills and abilities, attitude to a partner's personality, motivation and motivational conditions (such as attention, relevance, confidence, satisfaction) (Small \& Gluck, 1994). The level and forms of interaction between the interlocutor and candidates in each ST part are different and therefore these variables manifest themselves diversely, because under these testing conditions speaking is not simply a social amicable conversation, but a situation-based activity, information-related talk, assessed and timeconstrained. The candidates' "unplanned speech consisting of idea units ... and spoken on the spur of the moment in reaction to other speakers" (Luoma, 2004, p. 13) is assessed on the comprehensibility and accuracy (that is, three analytical criteria - grammar, vocabulary and pronunciation). Their abilities to create meaning in discourse, interactional efficiency and liveliness of expression are central elements in task performance (Luom, 2004) (that is, two more analytical criteria - discourse management and interactive communication). The applied criteria are naturally interpreted at the CAE level.

It is well-known that L1 and L2 speaking "consists of at least three stages: conceptualization, formulation, and articulation" (Thornbury, 2013, pp. 9-10) and the stage of formulating "involves making strategic choices at the level of discourse, syntax, and vocabulary" (Thornbury, 2013, p. 3). It is a paucity of appropriate L2 advanced vocabulary that really interferes with candidates' performance at the exam. The problem of vocabulary development and acquisition is acute, as "learners can attain an advanced level through active and passive knowledge of complex lexical units"
(Arnaud \& Savignon, 1997, p. 161), idioms, and specific or rare words.

As learners' motivation is defined "as the extent to which an individual works or strives to learn the language because of a desire to do so and the satisfaction experienced in this activity", this definition "involves three components: 1) motivational intensity or effort expended to learn the language, 2) a desire to learn the language, and 3) a positive attitude towards learning the language." (Purpura, 2004, p. 95). In this respect, all the candidates are predisposed to acquire and develop necessary skills because for them it is a high stakes certificate in terms of future career, effort, and time, as well as the exam cost. However, as any test remains very structure based, the candidates feel and experience washback, that is, the effect of testing on the teaching and learning, and some candidates may not understand correctly what the test items require of them (Davies, Brown, Elder, Hill, Lumley, \& McNamara, 1999; McNamara, 2000) and how they are assessed because assessment of oral proficiency is immensely complicated (Taylor, Weir, Coniam, Hawkey, \& Sunderland, 2008).

A further problem lies in the way learners evaluate their oral language proficiency. So much of language teaching over the years has shown that students, as a rule, cannot impartially assess the level of their personal knowledge at the beginning of the course. This inevitably leads to language and test anxiety problems later on. In fact, they are able to lay serious obstacles to the language teaching and learning process, as this proficiency test "aims to establish a candidate's readiness for a particular communicative role, for example, in a work or educational setting" (McNamara, 2000, p. 135).

\section{Aims of the Present Study}

As the facilitation of learning within the format of CAE is the goal of the instructional preparatory course of the Language Preparation Center in the National Research University Higher School of Economics (HSE) as well as at the Institute of Tourism and Hospitality (IT\&H) in Moscow, the nature of the above mentioned problems will be examined more closely and the ways of their remedies will be the focus of attention. It may be claimed that the purpose of the article is to assess the empirical veracity of the authors' observations in the changes of the students' value-orientations, motives, ways of problem-solving, essential linguistic skills both at the beginning and at the end of the course.

\section{Participants}


The preparatory CAE course is a commercial optional course which can be chosen by any student or adult person whose L2 proficiency level is not lower than B2-B2+. 92 students of two above-mentioned Moscow higher educational institutions took part in this study through personal contacts with the authors of the article. 30 - third- and fourth-year students of IT \&H, 60 were students of the HSE, mainly undergraduates (72) or sometimes postgraduates (20) (from 2000 (the year of the instructional preparatory course introduction) to 2014 (as in 2015 the exam format was altered)).

\section{The Questionnaire and Survey}

An open-ended questionnaire (a quantitative mode) (Appendix 2) was worked out to support the assessment of the data received with the help of the qualitative methods, though the authors are aware that "not everything that can be counted counts, and not everything that counts can be counted" (Cameron, 1963, p. 13). The candidates were asked to complete the questionnaires and surveys on a voluntary basis that is why only about 92 questionnaires were obtained and analyzed. It must be admitted that items in the questionnaires were added with the course of time due to the fact that in different groups the candidates' level of oral proficiency, test and language anxiety varied slightly and the items were randomized to avoid any biased item order. The most typical answers are presented, which, nevertheless, permit drawing some conclusions. One short open-ended survey (Appendix 3 and Figure 1) was developed and carried out at the end of the course to realize candidates' attitude towards the arising learning difficulties and the remedies for them in each part of the ST.

\section{Analysis of Russian Students' Predicaments and Tools of Their Remedies}

Manyyears' experience and the short questionnaires allowed the authors to elicit some responses from the candidates which turned out to be sufficient enough to ascertain the common problems arising during the course, infer some links, generalize and offer some solutions. Thus, it must be highlighted that doing Part 1 (for better understanding of the Speaking Test format see Appendix 1, Table 1) a number of students are very often not ready to present personal information, feel perplexed and sound unnatural, as they do not know each other and see "their partners as being extremely different from them in terms of extraversion" (O'Sullivan, 2004,p. 133) and perception. Some students feel embarrassed at having to speak about their native places (the level of life is lower there; therefore, even economic reasons can influence answers). Others have no wish to present true personal information to strangers and even explained their introversion by being superstitious. The easiest method for teachers is to introduce themselves first to alleviate the tension in class. The helpful technique is to suggest students ask their teacher personal questions or a teacher answers them together with students in turn.

Then one more problem arises in Part 1. In Past Papers textbooks there are questions which ask students to describe their negative experience or dislikes. Such questions really take them by surprise as many of them do not want to speak about negative experience because their classmates can make fun of them and such questions intimidate them.

'Out-dated' questions about newspapers and radio can paradoxically puzzle the candidates: they neither listen to the radio nor read newspapers as they keep up with the news on the Internet. Some questions containing not-widely-used tenses (Future Continuous/Perfect) can also cause some incomprehension. These problems can be completely eradicated by regular preparation in compliance with the exam requirements. A deeper understanding of them helps the candidates to cope with mock exam papers and their anxiety. Thus, they remember that their answers should not be long and prepared in advance; speaking about interests, daily routines, work/study "the candidates must give more personal detail, but they can't monopolize time" (Kenny \& Newbrook, 2008, p. 29). Besides, "the candidates should be confident in using correct grammatical forms" (French, 2003, p. 46), as the interlocutor asks questions about different periods of their lives. It is essential to answer what the candidates have been asked and "not to go off at a tangent to talk about something different" (Osborne \& Nuttall, 2009, p. 30). So, at this stage the main problems are test anxiety, personal uncertainty, perception of partners and some ignorance of the test requirements.

In Part II, the candidates usually speak in pairs. Each candidate in turn is given visual (1999-2008 format) and visual and written prompts (since December 2008 to 2014). In Hawkey's opinion, "written replications of task instructions ... increased candidates' confidence when undertaking the task ... and encouraged candidates to produce more varied, coherent and complex language than the picture tasks, which seemed to result in less complex language and more hesitation" (Hawkey, 2009, pp. 192-193).

The 1999-2008 format demanded the candidates be given a similar set of pictures but in a different order or two different sets, while the December 2008-2014 format offered only two different sets of 
pictures presenting different topics. In the former format, candidates B had to listen to candidates A very carefully as they could be asked to comment on the picture which had not been mentioned by candidates A. The comparative analysis shows that candidates B were inhibited about following their partners' answers because the pictures they had were practically the same.

However, the most important hindrance that can interfere with the candidates' successful performance at the exam is the misinterpretation of the topic subject matter. The topic 'Ambition' can be exemplified (French, 2009, Test 1). Some Russian candidates fail to fulfill the task because the Russian often negative meaning of the word "ambition" overlaps with the English connotation of the word. The candidates substantiate it on the basis of their first language: it corresponds to the English nouns "vanity, arrogance" describing disapproval, whereas the meanings in the entry of the Longman Exams Dictionary are quite positive and neutral. The same noun can be both countable ([C] 'a strong desire to achieve something'), and uncountable ([U] 'determination to be successful and powerful'), and, consequently, has different meanings.

Even at this level students of non-linguistic specializations are incapable of appreciating all merits of Learner's Dictionaries designed for nonnative speakers. Such dictionaries provide learners with additional patterns how to use the word correctly and mistakes are explained. The candidate should be taught to understand all the labels and not to ignore them, as they influence the thoroughness of their preparation. These special skills will help them to use good dictionaries to their advantage. Nevertheless, the answers given in the questionnaire are disappointing: none of the students state that they use special Learner's Dictionaries preferring on-line bilingual English-Russian dictionaries. The candidates justify such attitude by a lack of time and convenience which is unacceptable.

It can be stated that students can remember quite easily the requirements to use the special phrases to compare or contrast the pictures and learn them by heart as the textbooks provide lists of such expressions. So, the main problem in this part is some paucity of vocabulary and inability to use dictionaries to their advantage.

This problem can manifest itself and even aggravate in a collaborative task of Part III. Here, there is a serious lack of ideas and the topics of tasks can be real hiccups which cause delays in speaking. The answers quite often testify to the poor cultural competence of some candidates and the paucity of knowledge in other subjects. Obviously, profound knowledge of different significant world events can contribute to successful results. It must be admitted that not all the candidates realize the true meaning of the word 'lifelong' (as at this stage often their only ambition is to try to get a certificate): they must acquire and develop language skills to maintain their level of language proficiency. In the questionnaire the candidates elucidated their problems and failures to give satisfactory answers not by a lack of general knowledge, but by the fact that they simply could not remember the exact words they needed at the moment and that they did not expect that such a topic could be included into the test.

In Part IV the candidates are supposed to extend the discussion. "The candidates should be prepared to give their opinion, extend their responses by giving reasons and further details, interact with their partner and not dominate the conversation" (Speaking Test Preparation Pack for CAE, 2008, p. 19). The experience demonstrates that the candidates' main dilemma is what to say about and what language to use: they do not manage to provide more examples and repeat the same ideas using the limited vocabulary resource. The lack of ideas entails the usage of poor and inappropriate and sometimes even irrelevant vocabulary. One more common error is when the candidates share their partners' ideas.

The efficient way of acquiring ideas and the proper range of vocabulary is reading: the questionnaire shows that very few students try to read books in the original, the majority mention that they read only for their homework, so, the main task of the course is to inspire the candidates to read regularly, for instance, teachers can recommend or compile lists of short stories first, quoting some interesting ideas or collocations from them, then recommend some longer pieces. "Reading newspapers and magazines, watching films and English-language programs on TV/the Internet, listening to the radio or downloading podcasts of any topic of interest to them give the candidates ideas for things to say and help them to form their opinions about things" (Speaking Test Preparation Pack for CAE, 2008 , p. 16). This inevitably leads to a necessity to pay special attention to teaching more idiomatic language. Besides it is widely assumed (Lewis, 2000; Akhmanova \& Idzelis, 1978; and others) that many grammatical errors are caused by lexical deficiencies, and that "the best response to many of these errors at the advanced level is to do more lexical work in place of grammatical correction. ... Learners should put more emphasis on collocation and other lexical work" (Lewis, 2000, p. 17). It brings a more general problem: the responsibility of advanced learners for independent learning and the responsibility of teachers for choosing the scope of the most linguistically useful language items.

Finally, some CAE specifications cause misunderstanding: the candidates are not being assessed on their knowledge of the world. However, if they do not actually express any ideas, it will be difficult 
for examiners to give a fair appraisal of their language ability. Besides, the utterances must be arranged logically and relevantly. Another specification states answers with minor slips and non-impeding errors can get a high mark, as rarely answers are flawless. Nevertheless, candidates should endeavor to perfect their skills because "in the speech of foreign language learners errors can signal lack of knowledge" (Luoma, 2004, p. 19).

\section{Results and Discussion}

The in-depth research shows that in the beginning the candidates demonstrate eagerness to take the exam and are motivated, but they are not very well aware of the assessment criteria, requirements, and the content of the exam. The candidates' feedback confirms they do not mention test anxiety as a detrimental factor (the only concern is the number of partners). However, the most significant variables that affect their performance are language abilities and the topics of pictures. For the candidates the adjustment to the requirements does not pose many problems, while the main difficulty is the ability to acquire, develop and use a range of vocabulary: the idiomaticity of the language required really matters. Such important methods as probing questions, texts/literature, openended dilemmas, role playing, classroom discussion (Lewis, 2000, p. 186) must be applied to enlarge students' collocational input. "It may even be that unexpected combinations of familiar words are some of the most important and useful collocations from a pedagogical point of view" (Lewis, 2000, p. 136).

The enlarged vocabulary leads to autonomy and automacity in the language production (Thornbury, 2013). The research found that the learners use approximately the same lexicon in their speech but if they use a range of fixed phrases "they are perceived to be more fluent: fixed phrases are a proof of a higher level of ability, they contribute essentially to the message" (Luoma, 2004, pp. 18-19).

The course arouses learners' awareness of what learners' dictionaries offer. As Chan correctly reasons they should understand that the lifelong certificate means they must become "successful lifelong selflearners and learners' dictionaries are among easily accessible self-learning tools of a second language" (Chan, 2014, p. 33).

The attitude to the Internet dictionaries and other ambiguous sources alters. The Internet "affords searchable access to a vast array of pedagogical resources" (Kern, 2014, p. 341), but "what one sees on one's computer screen is a highly mediated, filtered version of the world" (Kern, 2014, p. 341). So the attitude to the obtained on-line information needs critical thinking and careful consideration.

Not to be baffled by the topic of the pictures, students should read regularly. The candidates fail at first to relate the genuine role of extensive reading "the magic carpet to language learning" - (Macalister, 2014, p. 389) to the L2 acquisition in ESL environment. As students are not accustomed to reading much in an L2 environment, the candidates often cannot choose correctly what exactly to read. Reading should become a habit which both facilitates language learning and contributes to vocabulary acquisition, spelling, and pronunciation. Reading is a benefit in test taking, as any good texts are priceless sources of ideas, information, and vocabulary. The survey reveals that the candidates change their views on reading, they fully appreciate the idea of it, as the link between the time-consuming process of reading and vocabulary acquisition is not a hoax.

The questionnaires posit similar findings: the candidates are more often exposed to non-native varieties of English through schooling, socialization and communication. In a foreign language context, learners have few opportunities to speak the language outside the classroom (Luoma, 2004) (see Appendix 4). However, in this regard, students of the IT \& $H$ very often outdo their peers from the HSE in fluency of the oral speech, as they have regular practice working in hotels, travel agencies, being part-time guides; it is an indispensable part of their student life and future career.

\section{Conclusion}

In sum, the results illustrate that various variables can either "encourage or discourage language learners' communicative interaction, both in natural and in instructional setting" (Khatib \& Nourzadeh, 2014, p. 270). Anxiety, timing, attitude to partners and perception of interlocutors can be somehow trained, but oral proficiency, language skills, vocabulary acquisition, socio-cultural competences should be permanently developed through reading authentic texts, aural practice, and using learners' dictionaries. Thus, the research provided valuable insight into the causes of candidates' problems while preparing for the ST. Although, self-made questionnaires, the validity and reliability of which have not been wellestablished, were applied, the questionnaires can be helpful for longitudinal studies of EFL learning. "For pedagogy, the questionnaires would be highly useful in helping compile inventories of learners' individual differences" (Khatib \& Nourzadeh, 2014, p. 278) and in further research and comparative analysis. 

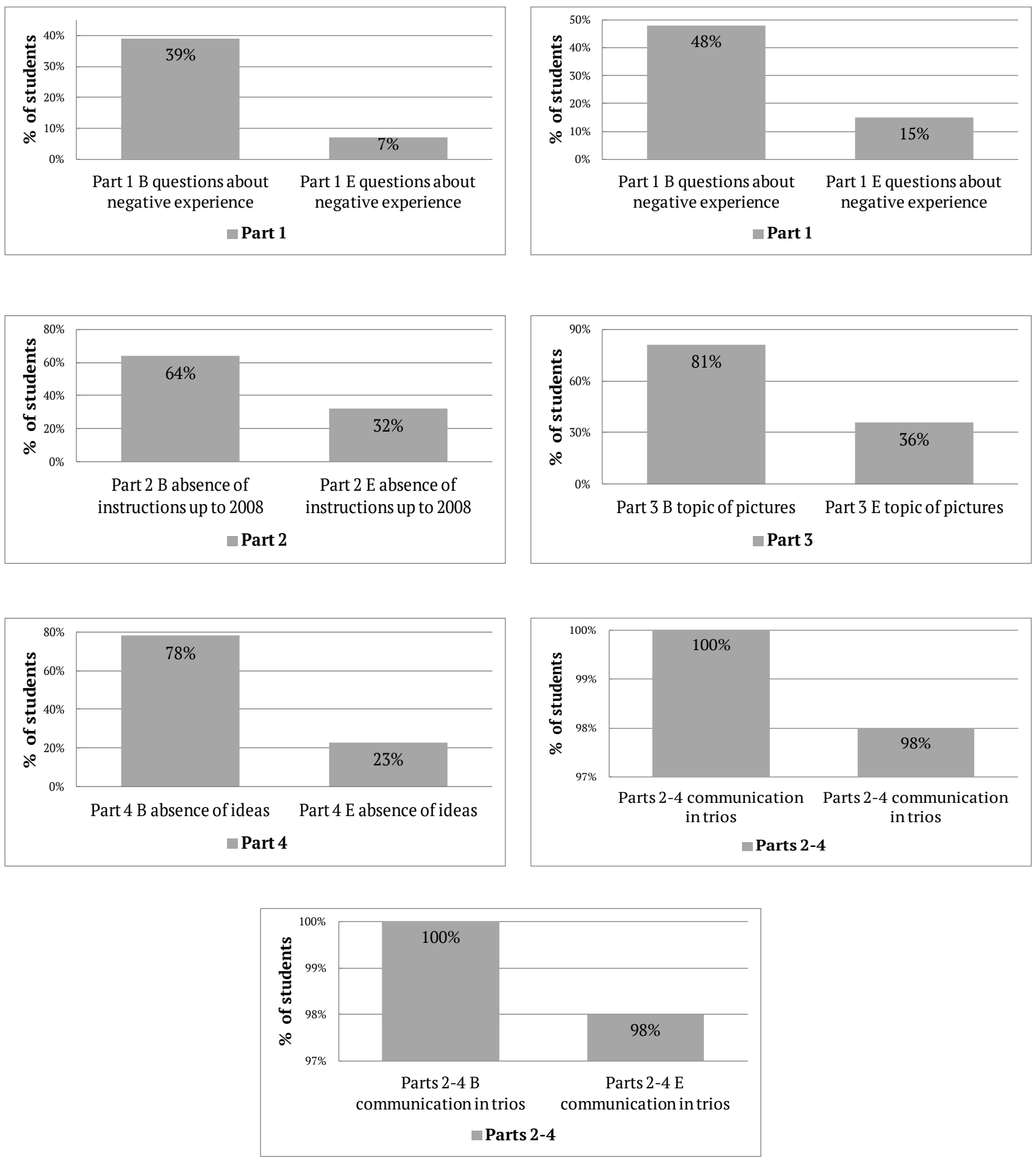

Figure 1. Results of the questionnaire and survey. Changes in candidates' attitude to arising learning difficulties at the beginning (B) and end (E) of the course in different Parts of the ST. 


\section{References}

Akhmanova, O., \& Idzelis, R. F. (1978). What is the English we use? A course in practical stylistics. Moscow, USSR: Moscow University Press.

Arnaud, P., \& Savignon, S. (1997). Rare words, complex lexical units and the advanced learners. In J. Coady \& T. Huckin (Eds.), Second language acquisition (pp.157-173). Cambridge, UK: Cambridge University Press.

Cameron, W. (1963). Informal sociology: A casual introduction to sociological thinking. New York, NY: Random House.

Chan, A. (2014). How can ESL students make the best use of learners' dictionaries? The International Review of the English Language. English Today, 119, 33-37.

Davies, A., Brown, A., Elder, C., Hill, K., Lumley, T., \& McNamara, T. (1999). Dictionary of language testing. Cambridge, UK: Cambridge University Press.

French, A. (2003). CAE testbuilder: Tests that teach. Oxford, UK: Macmillan.

French, A. (2009). CAE testbuilder: Tests that teach. New Edition. Oxford, UK: Macmillan.

Hamid, M. O. (2014). World Englishes in international proficiency tests. World Englishes, 33, 263-277.

Hawkey, R. (2009). Examining FCE and CAE: Key issues and recurring themes in developing the first certificate in English and certificate in advanced English exams, studies. In Language Testing (Vol. 28). Cambridge, UK: UCLES/Cambridge University Press..

Kenny, N., \& Newbrook, J. (2008). CAE practice tests plus. Edinburgh, UK: Pearson/Longman.

Kern, R. (2014). Technology as Pharmakon: The promise and perils of the Internet for foreign language education. The Modern Language Journal, 98, 340-357.

Khatib, M., \& Nourzadeh, S. (2014). Development and validation of an instructional willingness to communicate questionnaire. Journal of Multilingual and Multicultural Development, 36, 266-283.

Lewis, M. (2000). Language in the lexical approach. In M. Lewis (Ed.), Teaching collocation. Further developments in the lexical approach (pp. 126-154). Boston, MA: Thomson. Heinle.

Lewis, M. (2000). Materials and resources for teaching collocation. In M. Lewis (Ed.), Teaching collocation. Further developments in the lexical approach (pp. 186-204). Boston, MA: Thomson. Heinle.

Lewis, M. (2000). There is nothing as practical as a good theory. In M. Lewis (Ed.), Teaching collocation. Further developments in the lexical approach (pp. 1027). Boston, MA: Thomson. Heinle.

Luoma, S. (2004). Assessing speaking. Cambridge, UK: Cambridge University Press.

Macalister, J. (2014). Teaching reading: Research into practice. Language Teaching: Surveys and Studies, 47(3), 387-397.

McNamara, T. (2000). Language testing. Oxford, UK: Oxford University Press.

Meddingtons, L., \& Thornbury, S. (2009). Teaching unplugged. Peaslake, UK: DELTA Publishing.

Taylor, L., \& Weir, C. J. (Eds.). (2008). Multilingualism and assessment. In Studies in language testing (Vol. 27). Cambridge, UK: Cambridge University Press.

Norris, R. (2004). Ready for CAE. Oxford, UK: Macmillan.

Osborne, C., \& Nuttall, C. (2009). CAE practice tests. Boston, MA: Heinle.

O’Sullivan, B. (2004). Modelling factors affecting oral language test performance: A large-scale empirical study. In M. Milonovic \& C. Weir (Eds.), European language testing in a global context. Studies in language testing (Vol. 18, pp. 129-142). Cambridge, UK: Cambridge University Press.

Purpura, J. (2004). Validating questionnaires to examine personal factors in L2 test performance. In M. Milonovic \& C. Weir (Eds.), European language testing in a global context. Studies in language testing (Vol. 18, pp. 93-115). Cambridge, UK: Cambridge University Press.

Small, R. V., \& Gluck, M. (1994). The relationship of motivational conditions to effective instructional attributes: A magnitude scaling approach. Educational Technology, 34, 33-40.

Thornbury, S. (2013). How to teach speaking. Harlow, UK: Pearson.

UCLES. (2008). Speaking test preparation pack for CAE. Cambridge, UK: UCLES.

Winn, M. (2005). Collecting target discourse: The case of the US naturalization interview. In M. Long, (Ed.), Second Language Needs Analysis (pp. 265304). Cambridge, UK: Cambridge University Press. 


\section{Appendix 1}

Table 1

What happens in the ST (from Speaking Test Preparation Pack for CAE, 2008, p. 6; after Norris, 2004, p. 5; French, 2003, p.45-47, 83)

\begin{tabular}{|c|c|c|c|c|}
\hline Parts & $\begin{array}{c}\text { Timing } \\
\text { (minutes) }\end{array}$ & $\begin{array}{l}\text { What the interlocu- } \\
\text { tor does }\end{array}$ & What a candidate does & Possible range of language used \\
\hline 1. Interview & 3 & $\begin{array}{l}\text { asks individual direct } \\
\text { questions }\end{array}$ & gives personal information & $\begin{array}{l}\text { General interactional and social language: } \\
-\quad \text { giving personal information about everyday } \\
\text { circumstances } \\
\text { - } \quad \text { expressing opinions } \\
\text { - } \quad \text { talking about interests and experiences }\end{array}$ \\
\hline $\begin{array}{l}\text { 2. Individual } \\
\text { long/short } \\
\text { turn }\end{array}$ & 4 & $\begin{array}{l}\text { asks each candidate to } \\
\text { talk about two visuals } \\
\text { for } 1 \text { minute and com- } \\
\text { ment on the pictures } \\
\text { for } 30 \text { seconds }\end{array}$ & $\begin{array}{l}\text { expresses opinions through } \\
\text { comparing and contrasting } \\
\text { and comments briefly on the } \\
\text { other candidate's pictures }\end{array}$ & $\begin{array}{l}\text { Organizing an extended piece of discourse: } \\
-\quad \text { comparing and contrasting } \\
-\quad \text { expressing opinions } \\
-\quad \text { describing } \\
-\quad \text { speculating and hypothesizing } \\
-\quad \text { commenting }\end{array}$ \\
\hline $\begin{array}{l}\text { 3. Collaborative } \\
\text { task }\end{array}$ & 4 & $\begin{array}{l}\text { asks candidates to } \\
\text { talk together using } \\
\text { visual prompts }\end{array}$ & $\begin{array}{l}\text { discusses a problem-solving } \\
\text { task with a partner, exchanges } \\
\text { ideas and opinions, makes } \\
\text { suggestions, agrees, disagrees, } \\
\text { and initiates discussion }\end{array}$ & $\begin{array}{ll}\text { Sustaining an interaction: } \\
-\quad \text { exchanging ideas } \\
-\quad \text { inviting and responding to opinions } \\
-\quad \text { agreeing and/or disagreeing } \\
-\quad \text { suggesting } \\
-\quad \text { speculating } \\
-\quad \text { evaluating through negotiation, discussing, } \\
\quad \text { selecting etc. } \\
\text { - } \quad \text { reaching a decision }\end{array}$ \\
\hline $\begin{array}{l}\text { 4. Discussion on } \\
\text { topics related } \\
\text { to Part } 3\end{array}$ & 4 & $\begin{array}{l}\text { leads a discussion, } \\
\text { asks more general and } \\
\text { abstract questions }\end{array}$ & $\begin{array}{l}\text { exchanges views and opinions, } \\
\text { further discusses the issues or } \\
\text { themes raised in Part } 3\end{array}$ & $\begin{array}{ll}- & \text { expressing and justifying opinions } \\
\text { - } & \text { agreeing and/or disagreeing } \\
\text { - } & \text { developing the conversation as much as possible }\end{array}$ \\
\hline
\end{tabular}




\section{Appendix 2}

\section{Questionnaire}

\begin{tabular}{|c|c|}
\hline Questions & Typical answers \\
\hline 1. Do you read English classic books in the original? & Tried, but it is very difficult and time-consuming. \\
\hline 2. Do read English modern books in the original? & Very rarely, no free time. \\
\hline 3. Do you read English newspapers? & Only professional articles as homework. \\
\hline 4. Do you listen to English radio stations? & Never. \\
\hline 5. What sources of the English language do you have? & $\begin{array}{l}\text { Classes at university, the Internet, cinema, foreign friends } \\
\text { (mainly non-native speakers). }\end{array}$ \\
\hline 6. Do you use bilingual or monolingual dictionaries? & Mainly English-Russian on-line dictionaries. Convenient. \\
\hline $\begin{array}{l}\text { 7. When you consult dictionaries, do you read only the explanation of } \\
\text { the word meaning or examples? }\end{array}$ & Only the explanation usually to understand the meaning. \\
\hline 8. Do you pay attention to the different labels used in the dictionary? & What do you mean? \\
\hline $\begin{array}{l}\text { 9. Have you ever used a dictionary of synonyms, antonyms, collocations } \\
\text {...? }\end{array}$ & $\begin{array}{l}\text { 1) Find everything on the Internet. } \\
\text { 2) Are there such dictionaries? }\end{array}$ \\
\hline 10. Have you ever used Advanced Learner’s Dictionary? & $\begin{array}{l}\text { Prefer on-line dictionaries and } \\
\text { pay no attention to the type of dictionary. }\end{array}$ \\
\hline $\begin{array}{l}\text { 11. Where, when and with whom do you have a chance to communicate } \\
\text { in English? }\end{array}$ & $\begin{array}{l}\text { 1) Only while travelling; } \\
\text { 2) Have some acquaintances abroad, but non- native speak- } \\
\text { ers; } \\
\text { 3) On the Internet, mainly non-native speakers; } \\
\text { 4) In summer sometimes go to England; } \\
\text { 5) Have a part time job in summer in hotels and travel agen- } \\
\text { cies, some guests are native speakers. }\end{array}$ \\
\hline 12. Can you describe your negative experience in class? & $\begin{array}{l}\text { 1) Not ready to speak about failures. } \\
\text { 2) Don't want to be laughed at. }\end{array}$ \\
\hline
\end{tabular}




\section{Appendix 3}

Survey. Candidates' attitude to arising learning difficulties and the remedies for them (the end of the course).

\begin{tabular}{lll}
\hline Part of the ST & \multicolumn{1}{c}{$\begin{array}{c}\text { Problem } \\
\text { (typical answers) }\end{array}$} & \multicolumn{1}{c}{ Remedies } \\
\hline Part 1 & Questions about negative experience & Got accustomed to them and do not feel any anxiety. \\
\hline Part 2 & $\begin{array}{l}\text { The topic of the pictures } \\
\text { The necessity to remember the in- } \\
\text { structions (1999-2008 format) }\end{array}$ & $\begin{array}{l}\text { 1. } \quad \begin{array}{l}\text { Must read more to develop vocabulary. } \\
\text { Must use learners' dictionary }\end{array} \\
\text { 2. Will concentrate more on them. }\end{array}$ \\
\hline Part 3 & The topic of the pictures & $\begin{array}{l}\text { Must enlarge the range of both vocabulary and gram- } \\
\text { matical forms, read texts of different styles and genres. }\end{array}$ \\
\hline Part 4 & Absence of ideas & $\begin{array}{l}\text { Must read more to develop vocabulary and to get more } \\
\text { information in order to speak without halting. }\end{array}$ \\
\hline The whole ST & Communication in a group of three & Had some speaking practice in a group of three. \\
\hline
\end{tabular}

\section{Appendix 4}

\section{The Picture of an Average Test-taker}

An average test-taker is a Russian-speaking B2+-C1-level undergraduate student of non-linguistic specializations who is pressed for time and that is why very rarely reads anything but professional literature which is compulsory for his academic studies. $\mathrm{He} /$ she has a vague idea about the way monolingual dictionaries are used. The usage of English is limited to oral communication mainly with non-native speakers in the classroom environment or while travelling abroad for all that he/she avoids discussing negative experience. 